\title{
Angular Photogrammetric Analysis of the Soft Tissue Facial Profile of Iranian Young Adults
}

\author{
Shabnam Ajami, ${ }^{1, *}$ Hooman Zarif Najafi, ${ }^{1}$ and Sareh Mahdavi ${ }^{2}$ \\ ${ }_{1}^{1}$ Department of Orthodontic, Orthodontic Research Center, School of Dentistry, Shiraz University of Medical Sciences, Shiraz, IR Iran \\ ${ }^{2}$ Students Research Committee, School of Dentistry, International Branch, Shiraz University of Medical Sciences, Shiraz, IR Iran \\ *Corresponding author: Shabnam Ajami, Department of Orthodontic, Orthodontic Research Center, School of Dentistry, Shiraz University of Medical Sciences, Shiraz, IR \\ Iran. Tel: +98-9173143440, E-mail: dr.ajami.sh@gmail.com
}

Received: 2015 October 11 ; Accepted: 2015 December 8.

\begin{abstract}
Background:The evaluation of the soft tissue facial profile is essential to achieve facial harmony in orthodontic diagnosis and treatment planning.

Objectives: This study aimed to develop soft tissue angular photogrammetric norms for a sample of Iranian population.

Patients and Methods: Standardized profile photographic records were taken from 34 men and 37 women. Twelve measurements were analyzed on each photograph by AutoCad software. For statistical evaluation a Student's t-test was used and the reliability of the method was assessed by using Intra-class Correlation Coefficient (ICC) within a four week interval.

Results: Three of the angles showed sexual differences: nasofrontal (G-N-Prn, $\mathrm{P}=0.009)$, nasal $(\mathrm{Cm}-\mathrm{Sn} / \mathrm{N}-\mathrm{Prn}, \mathrm{P}=0.012)$ and vertical nasal $(\mathrm{N}-\mathrm{Prn} / \mathrm{TV}, \mathrm{P}=0.029)$. Other nine angles showed statistically insignificant gender differences $(\mathrm{P}>0.05)$. Two of the angles that suggested gender differences were wider in females: nasofrontal and nasal angle while the third angle was wider in males. Other angles such as nasolabial (Cm-Sn-Ls), mentolabial (Li-Sm-Pg), nasal dorsum (N-Mn-Prn) and angle of the total convexity (G-Prn-Pg) were also found wider in females. The inferior third was larger than the middle third. Mentolabial angle (Li-Sm-Pg), which had the highest standard deviation, showed the greatest variability.

Conclusions: The results showed gender dimorphism in three of the measurements: the nasofrontal, the nasal and the vertical nasal angles. Another significant finding was the large variability for the mentolabial angle. The result of this measurement should be assessed with caution.
\end{abstract}

Keywords: Angular Photogrammetry, Orthodontics, Facial Profile, Soft Tissue Analysis

\section{Background}

With no doubt, the most important feature of the human body is the face. It is part of the body which draws the most attention and is probably the part that people mostly are sensitive about in terms of esthetics (1). Physical appearance, in particular, facial features are well-known to impact psychological well-being and the self-esteem of an individual, which can affect one's social life and acceptance $(2,3)$. As such, there is strong interest in the study of dento-facial features for the purpose of enhancing the treatment results and ensuring harmonious facial appearance and optimal functional occlusion (4). As different racial and ethnic groups and genders have different norms and standards for facial features $(1,5)$, it is important for surgeons to customize treatment plans based on facial patterns and proportions that are consistent with an individual's demographics $(6,7)$. This could help in creating a more natural and aesthetically acceptable appearance relative to demographic standards of each individual (8). Maxillofacial, plastic surgeons and orthodontics alter facial appearance by procedures done on one or more facial features. As one of the main goals of these changes is to achieve facial harmony, the evaluation of the soft tissue profile is essential in diagnosis and treatment planning $(9,10)$. Various studies have been conducted for assessing variations and standards of dento-facial features. Among the notable, include analysis of soft tissue, craniofacial structure and facial balance $(11,12)$. Some authors have determined soft tissue parameters by cephalometries (13). Various studies have also described soft tissue facial analysis based on standardized photogrammetric methods $(14,15)$. Among these study methods available for soft tissue analysis, photogrammetry (i.e. analysis of photographs) is regarded as the conventional and more intuitive approach for analysis of soft tissue $(16,17)$.

\section{Objectives}

Since soft tissue paradigm is the essential for orthodon-

Copyright (C) 2015, Iranian Journal of Orthodontics. This is an open-access article distributed under the terms of the Creative Commons Attribution-NonCommercial 4.0 International License (http://creativecommons.org/licenses/by-nc/4.0/) which permits copy and redistribute the material just in noncommercial usages, provided the original work is properly cited. 
tic treatment in recent years, this study seeks to develop photogrammetric soft tissue angular norms for a sample of Iranian population of 16 - 30 years age group with class I skeletal and dental occlusion selected based on cephalometric analysis and also, to find if there is any sexual dimorphisms in any of these angular measurements in this Iranian samples.

\section{Patients and Methods}

This cross sectional analysis was conducted in the orthodontic department of Shiraz school of dentistry between October 2013 and June 2014. Lateral cephalograms of 400 Iranian adults who have attended clinic for orthodontic treatment were obtained randomly. A sample of 71 individuals (34 males and 37 females) was chosen among them. The sample size was determined using a simple sampling method based on previous trials. For the sample selection the following inclusion criteria were used:

1) 16 - 30 years of age (to reduce the effect of aging on facial dimensions)

2) Skeletal class I occlusion with minor crowding

3) No previous history of face trauma, plastic surgery or orthodontic therapy

4) No clinically obvious asymmetry and disharmony of the face

5) Parents and grandparents should be Iranian

The study complied with current ethical guidelines of the 1975 declaration of Helsinki. All patient information maintained under strict confidentiality and de-identified after initial data collection. Written consent was obtained from photographed subjects. The cephalograms were scanned with a Fujitsu scanner (output resolution: up to $600 \mathrm{dpi}$, speed: 200 or $300 \mathrm{dpi}$, letter, color, gray scale and monochrome, simplex: 135 ppm, duplex: 270 ipm). Cephalometric tracing for detecting skeletal class I cases was done by Onyx Ceph image software in different dimensions (developer and manufacturer of the cephalometric software Onyx Ceph is the enterprise Image Instruments $\mathrm{GmbH}$ with company headquarters in Chemnitz, Germany). Photographic set-up consisted of a tripod (Soligor, DT-310, Leinfelden-E, Germany), a digital camera (Canon EOS 60D, Japan) and a primary flash. In order to take a profile photograph of the patient the camera was set up and placed on an adjustable tripod which could be positioned according to the subject's height. With the subject's body height as the reference, the tripod ensured correct horizontal position of the lens optimal axis by controlling stability and height. To preserve the natural proportions of the subject, a 100 $\mathrm{mm}$ focal lens was used. The red-eye effect was circumvented by orienting the main flash 75 degrees from the upper right angle and $27 \mathrm{~mm}$ from the camera's optical axis. Another piece of the set-up was the secondary flash: positioned behind the subject to brighten the background and remove unwanted shadows from the contours of the facial profile The camera was used in its manual position with 1/60 shutter speed, f/9 diaphragm opening and ISO 200. Photographs were taken in natural head position (NHP). Facial orientation for photography was facilitated by a mirror, adjustable vertically in relation to the subject's height and positioned $120 \mathrm{~cm}$ in front of the patient. The subject-camera distance was about $2 \mathrm{~m}$. The subjects were asked to remove their glasses if they had any, stand in front of a mirror with head positioned upright, eyes looking into the mirror with lips at rest and arms positioned at their sides. The photographer made sure that the patient's forehead, neck and ears were obviously in view. All images were transferred to a computer and reference points were digitally marked on each photograph with AutoCAD software (Figure 1 and Table 1). Angular measurements of the analysis were also done by the same operator (CAD) to minimize margin of error (Table 2) and (Figures 2 - 4).

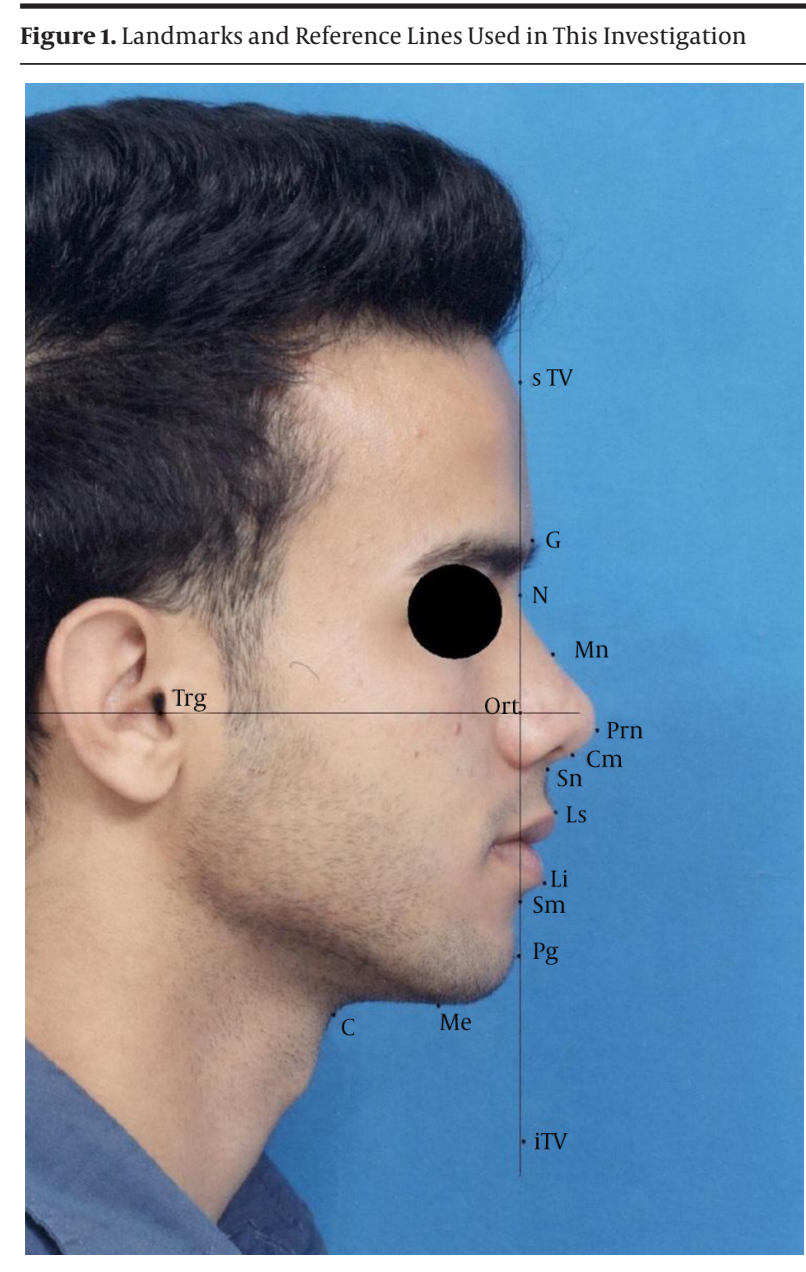

Abbreviations: G, glabella; N, nasion; Mn, midnasal; Prn, pronasal; Cm, columella; Sn, subnasal; Ls, labial superior; Li, labial inferior; Sm, supramental; Pg, pogonion; Me, menton; C, cervical; Trg, tragus; sTV, superior point of true vertical; iTV, inferior point of true vertical; Ort point, junction of true vertical and true horizontal. Reference lines: sTV-iTV, true vertical; N-Ort (parallel to TV through nasion), true vertical in nasion; Trg-Ort (perpendicular to TV through Trg), true horizontal (TH). 
Ajami S et al.

Table 1. Landmarks and Reference Lines Used in the Facial Profile Analysis

\begin{tabular}{|c|c|}
\hline Landmark/Reference Line & Description \\
\hline G, glabella & The most anterior point on the middle line of the forehead \\
\hline $\mathbf{N}$, nasion & The deepest point in the middle in the frontonasal curve \\
\hline Mn, midnasal & The midpoint on the dorsum of the nose between its root and tip \\
\hline Prn, pronasal & The most prominent point on the apex of the nose \\
\hline Cm, columella & The most anterior and inferior point on the apex of the nose \\
\hline Sn, subnasal & The deepest point in the nasolabial curvature \\
\hline Ls, labial superior & The upper lip vermillion border \\
\hline Li, labial inferior & The lower lip vermillion border \\
\hline Sm, supramental & The deepest point in the inferior sublabial concavity \\
\hline Pg, pogonion & The most anterior point of the chin \\
\hline Me, menton & The most inferior point on the inferior edge of the chin \\
\hline C, cervical & The deepest point at the angle of the chin and neck \\
\hline Trg, tragus & The most posterior point of the auricular tragus \\
\hline TV(N), TV line & A straight line through nasion parallel to the TV line \\
\hline TH, true horizontal line & A straight line through tragus perpendicular to the TV line \\
\hline
\end{tabular}

Table 2. Angular Measurements of the Analysis

\begin{tabular}{lc}
\hline Parameters & Description \\
\hline G-N-Prn & Nasofrontal angle \\
\hline Cm-Sn-Ls & Nasolabial angle \\
\hline Li-Sm-Pg & Mentolabial angle \\
\hline Cm-Sn/N-Prn & Nasal angle \\
\hline N-Mn-Prn & Angle of the nasal dorsum \\
C-Me/G-Pg & Cervicomental angle \\
\hline N-Trg-Sn & Angle of the medium facial third \\
\hline Sn-Trg-Me & Angle of the inferior facial third \\
\hline Sn-Sm/TH & Angle of the head position \\
G-Sn-Pg & Angle of facial convexity \\
\hline G-Prn-Pg & Angle of total facial convexity \\
\hline N-Prn/TV(N) & Vertical nasal angle \\
\hline
\end{tabular}

The Statistical Package for the Social Sciences SPSS 20.0 (SPSS Inc, Chicago, IL) software for windows was used for data analyzing. To compare male and female a Student's t -test was used. In order to assess the method error, 25 photographs were randomly selected, redigitalized and remeasured within a 4 week interval after the first evaluation by the same program (AutoCad software). The reliability and reproducibility of the method was determined using intra-class correlation coefficient (ICC). ICC showed significant consistency between the main and repeated records (Table 3).

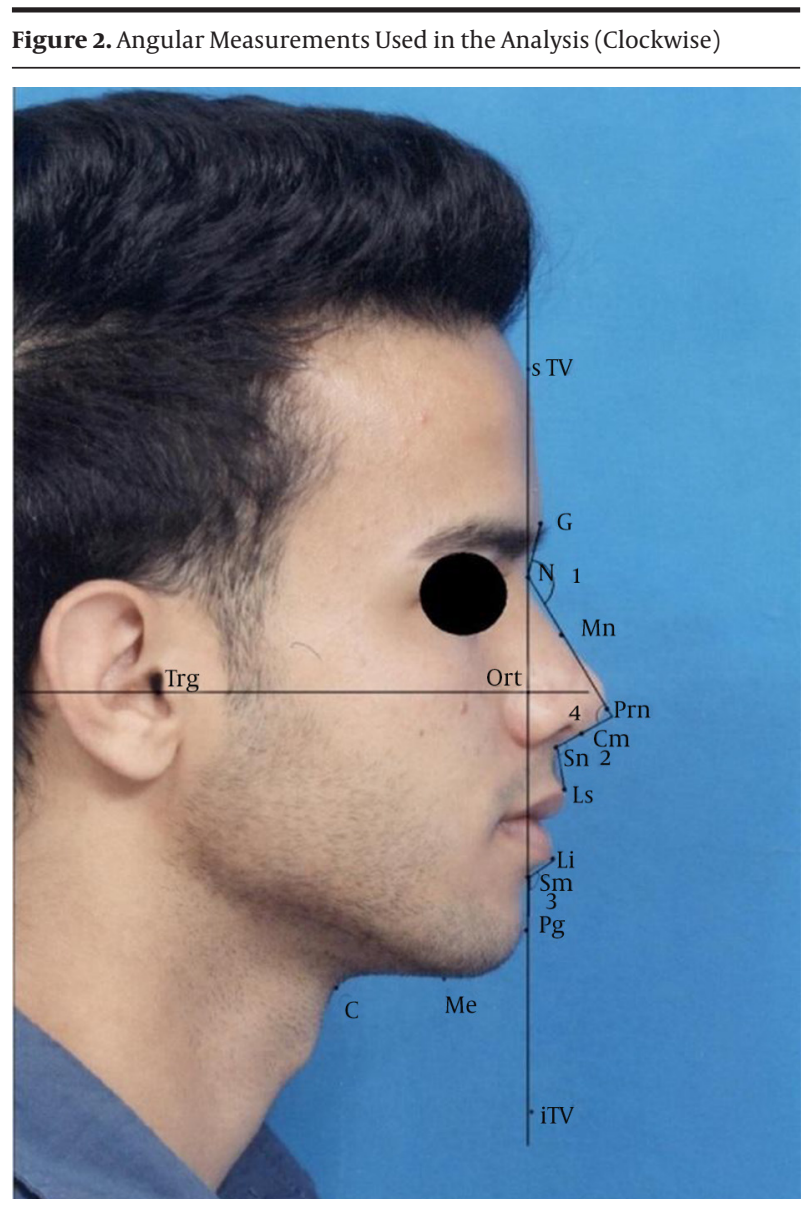

1, N-G-Prn, Nasofrontal angle; 2, Cm-Sn - Ls, Nasolabial angle; 3, Li - Sm- Pg, Mentolabial angle; 4, Cm-Sn/N-Prn, Nasal angle. 
Ajami S et al.

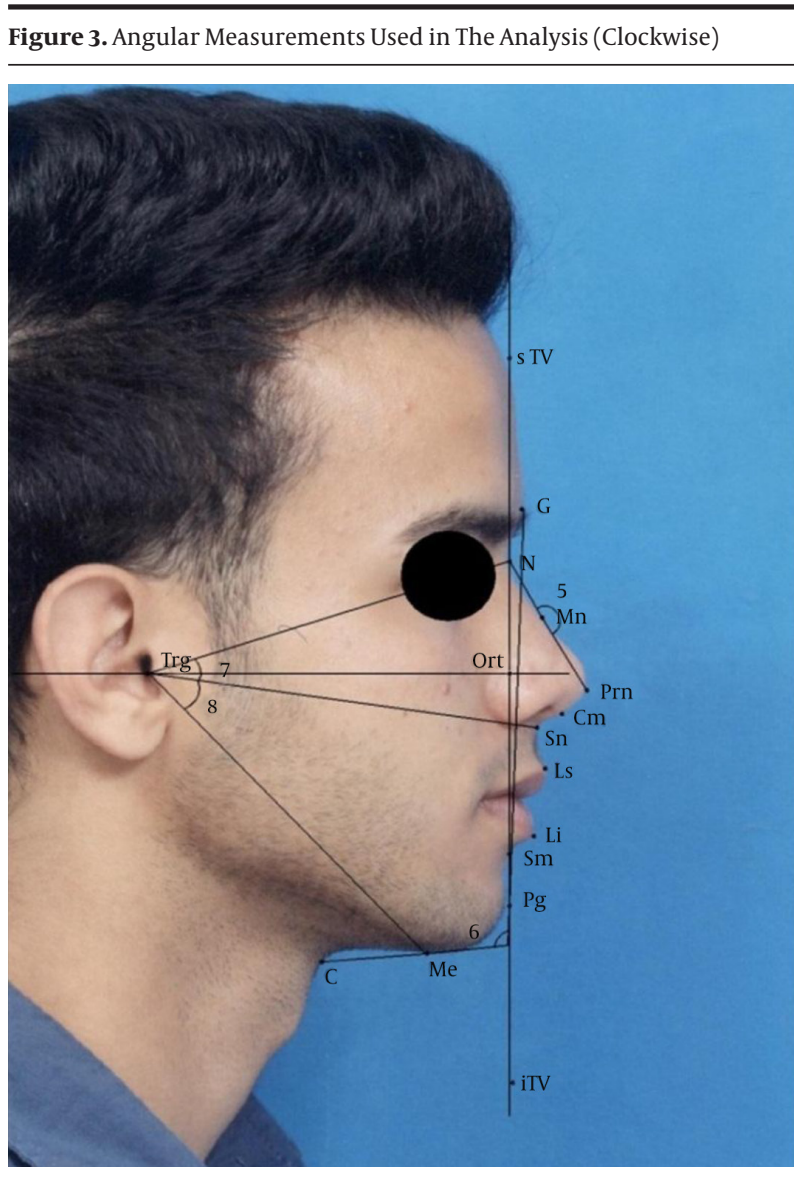

5, N- Mn- Prn; Angle of the nasal dorsum; 6, C-Me/G-Pg; Cervicomenta angle; 7, N-Trg-Sn; Angle of the medium facial third; 8, Sn-Trg -Me; Angle of the inferior facial third.

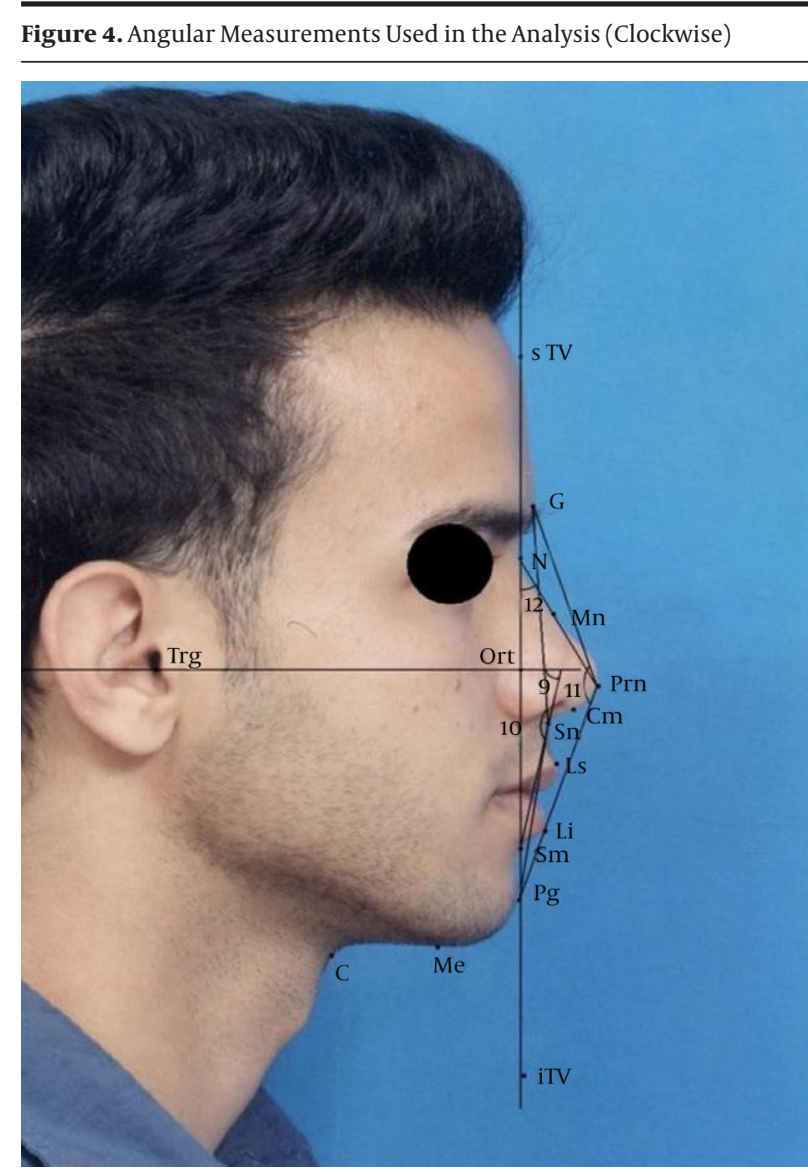

9, Sn-Sm/TH; Angle of the head position;10, G-Sn-Pg; Angle of facial convexity; 11, G-Prn-Pg; Angle of total facial convexity; 12, N- Prn/TV; Vertical nasal angle.

\begin{tabular}{lcc}
\hline Table 3. Method Error According to ICC (Intra-class Correlation Coefficient) & \\
\hline Parameters & ICC & P Value (Based on t-Test) \\
\hline G-N-Prn & 0.999 & $<0.001$ \\
Cm-Sn/N-Prn & 0.999 & $<0.001$ \\
\hline N-Prn/TV(N) & 0.997 & $<0.001$ \\
\hline N-Mn-Prn & 0.999 & $<0.001$ \\
Cm-Sn-LS & 1.000 & $<0.001$ \\
Li-Sm-Pg & 1.000 & $<0.001$ \\
C-Me/G-Pg & 0.999 & $<0.001$ \\
N-Trg-Sn & 0.982 & $<0.001$ \\
Sn-Trg-Me & 1.000 & $<0.001$ \\
Sn-Sm/TH & 1.000 & $<0.001$ \\
G-Sn-Pg & 0.998 & $<0.001$ \\
\hline G-Prn-Pg & 0.998 & $<0.001$ \\
\hline
\end{tabular}

\section{Results}

Our sample was consisted of 71 individuals (34 males, $47.9 \%$ and 37 females, $52.1 \%$ ) with a mean age of $22.56-3.87$. Demonstrates descriptive statistics data at Table 4 , includ- ing mean, maximum, minimum and standard deviation, for Iranian males and also shows the results of student's t-test for all variables to determine the influence of gen- 
der on the measurements. Three of the angles showed gender differences: nasofrontal (G-N-Prn, P = 0.009), nasal $(\mathrm{Cm}-\mathrm{Sn} / \mathrm{N}-\mathrm{Prn}, \mathrm{P}=0.012)$ and vertical nasal $(\mathrm{N}-\mathrm{Prn} /$ $\mathrm{Tv}, \mathrm{P}=0.029)$. Other nine angles showed statistically insignificant gender differences $(\mathrm{P}>0.05)$. Two of angles that suggested gender differences were wider in females: nasofrontal (G-N-Prn, females $=148.785 .88$ degrees, males $=144.677 .02$ degrees $)$ and nasal angle (Cm-Sn/N-Prn, females $=82.436 .29$ degrees, males $=78.057 .94)$. Vertical nasal (N-Prn/Tv), the third angle that presented sexual dimorphism, was wider in males (24.58 4.95 degrees) than in females (22.373.29 degrees). Other angles such as naso- labial (Cm-Sn-Ls), mentolabial (Li-Sm-Pg), nasal dorsum (N-Mn-Prn) and angle of the total convexity (G-Prn-Pg) were also found wider in females. Angle of the medium facial third (N-Trg-Sn), angle of the head position (Trg-Or/ Sn-Sm) and angle of facial convexity (G-Sn-Pg) were similar in both groups. The inferior third was larger (males $=$ 39.503 .32 degrees, females $=38.622 .61$ degrees) than the middle third ( males $=28.642 .25$ degrees, females $=28.83$ 1.87 degrees), but both these angles presented no gender dimorphisms. Mentolabial angle (Li-Sm-Pg), had the highest standard deviation and thus carried the greatest variability.

Table 4. Descriptive Statistical Data and Application of the Student's t-test in Relation to Gender ${ }^{\mathrm{a}}$

\begin{tabular}{|c|c|c|c|c|c|}
\hline Variable & Mean & SD & Minimum & Maximum & P Value (Based on t-Test) \\
\hline G-N-Prn & & & & & .009 \\
\hline Male & 144.67 & 7.02 & 126 & 157 & \\
\hline Female & 148.78 & 5.88 & 132 & 160 & \\
\hline Cm-Sn/N-Prn & & & & & .012 \\
\hline Male & 78.05 & 7.94 & 64 & 91 & \\
\hline Female & 82.43 & 6.29 & 71 & 94 & \\
\hline N-Prn/TV(N) & & & & & .029 \\
\hline Male & 24.58 & 4.95 & 14 & 37 & \\
\hline Female & 22.37 & 3.29 & 16 & 28 & \\
\hline N-Mn-Prn & & & & & .472 \\
\hline Male & 176.23 & 8.38 & 158 & 193 & \\
\hline Female & 177.48 & 6.08 & 168 & 196 & \\
\hline Cm-Sn-Ls & & & & & .375 \\
\hline Male & 100.26 & 11.39 & 84 & 121 & \\
\hline Female & 102.89 & 13.24 & 69 & 131 & \\
\hline Li-Sm-Pg & & & & & .874 \\
\hline Male & 131.82 & 15.47. & 107 & 192 & \\
\hline Female & 132.32 & 10.81 & 105 & 152 & \\
\hline C-Me/G-Pg & & & & & .081 \\
\hline Male & 102.73 & 9.25 & 83 & 125 & \\
\hline Female & 98.78 & 9.48 & 78 & 119 & \\
\hline N-Trg-Sn & & & & & .699 \\
\hline Male & 28.64 & 2.25 & 24 & 35 & \\
\hline Female & 28.83 & 1.87 & 26 & 34 & \\
\hline Sn-Trg-Me & & & & & .218 \\
\hline Male & 39.50 & 3.32 & 32 & 46 & \\
\hline Female & 38.62 & 2.61 & 33 & 44 & \\
\hline Sn-Sm/TH & & & & & .945 \\
\hline Male & 78.67 & 5.81 & $70-$ & 91 & \\
\hline Female & 78.59 & 4.10 & 71 & 88 & \\
\hline G-Sn-Pg & & & & & .711 \\
\hline Male & 166.29 & 4.89 & 154 & 175 & \\
\hline Female & 166.67 & 4.10 & 159 & 172 & \\
\hline G-Prn-Pg & & & & & .463 \\
\hline Male & 137.35 & 4.92 & 127 & 149 & \\
\hline Female & 138.08 & 3.28 & 131 & 147 & \\
\hline
\end{tabular}

${ }^{\mathrm{a}}$ Male, $\mathrm{n}=34$; Female, $\mathrm{n}=37$. 


\section{Discussion}

The purpose of this study was to determine the angular facial norms in the Iranian population between 16 and 30 years of age with skeletal class I occlusion and to discover any sexual dimorphisms in the angular measurements. Many factors, such as ethnicity, are known to impact facial soft tissue profile (18). The inclusion criteria and overall design of this study was specifically devised to identify normative values for the young Iranian population, which could be used to improve treatment plans in creating facial patterns consistent with accepted norms and a more natural look $(6,7,19,20)$. Patients who had undergone orthodontic or facial surgical treatment or subjects with obvious asymmetry or disharmony of facial features were excluded from this study as their artificial features may have confounded our study intended to characterize natural patterns. This study examined patients with normal skeletal class I occlusion, which may not necessarily reflect facial features considered aesthetically pleasing. However, the goal of this study was as an objective characterization of the typical and natural facial features in the young Iranian population, rather than confound the subjectivity of perceived beauty (21). This type of assessment is consistent with other major studies in this field for other population sub-groups (18). In addition, to ensure evaluating the normative values of the young Iranian population, subjects with known non-Iranian lineage (as could be discerned within the past 2 generations) were excluded. The ability to more easily utilize photogrammetric analysis in the clinical settings is one major driver for selecting this method for this study. In addition to its clinical accessibility, it has made data collection and analysis more efficient and effective. Other available major methods are at a disadvantage, as they necessitate costly equipment and more time consuming data collection (18). However, in the case of photogrammetric analysis, only relatively inexpensive equipment and simple procedures are needed to achieve reliable and solid analysis. Photogrammetric analysis allows us to readily utilize digital computation and computer-powered data analysis (18). This provides the means to produce graphical representations and perform complex statistical computations, which further extends our capabilities in profile analysis. Furthermore, unlike other available methods, subjects are not exposed to radiation, thus, making it a safer method for population based studies (22). As mentioned, one significant, noteworthy benefit of photogrammetric-based results is their accessibility for clinicians and easier application in clinical practice. Most plastic surgeons primarily use photographs for total facial aesthetics procedures (23); and when using angular measurements, there is no confounding impact by image re-sizing, and thus, easing its clinical application for both pre-operative planning and post-operative follow-up $(18,24)$. To assess whether sexual dimorphisms exist in the angular facial norms of the population studied in this study, our data analysis focused on comparing the angular data between the female and male gender subgroups. Our analysis showed statistically significant differences (at a 95\% confidence level) between male and female sub-groups in only a few of the measurements: the nasofrontal angle (N-G-Prn), nasal angle (Cm-Sn/N-Prn), and vertical nasal angle (N-Prn/TV). All other measurements showed no statistically significant differences between male and female sub-groups. Judging by this statistical analysis alone, one would conclude many similarities in facial norms between the female and male gender. We challenged the validity of this assessment by considering the variables that could have confounded ability to resolve statistical differences. From a standpoint of subject selection, we found no known or discernible population biases within the defined criteria that would have skewed our data (such as a high ratio of subjects originating from the same familial or tribal background). Data "noise" originating from the setup, data collection methods and measurements was considered. However, while a small level of noise is expected from these sources, no cause for significant levels of data "noise" could be gathered. Furthermore, sample sizes were relatively balanced between male and female subgroups with significant data points for each $(\mathrm{N}>30)$ to conduct a reasonable statistical analysis. Thus, the resulting standard deviations for the various sub-groups are likely to be strongly reflective of actual sampled variability and we consider the lack of significant differences in the majority of angular measurements to be real. In comparison with other similar studies investigated other population sub-groups, there are similarities however interesting differences when compared to the Iranian sub-population in our study, as expected when comparing ethnic and racial groups. However, it should be noted that the methodology used in our study, while fundamentally similar, was not identical to other photogrammetric studies in this field. In many respects, our methodology most closely resembles that of Malkoc et al. (18), which is a well-reputed study and has been referenced and used for comparisons in other ethnic and racialbased photogrammetric studies. While, any small differences in our methods could have introduced some level of bias in our data, no cause or reason for significant bias is identified. Thus, a macro-level and qualitative comparison is deemed valid for the purposes of assessing broad, overall differences of angular norms across different ethnic and racial sub-populations studied with using similar methods as the present study. And thus, the comparisons below between the results of our study with other benchmark studies are merely qualitative and do not assess statistical significance across datasets from different studies. We found statistically significant gender differences in nasofrontal angle (G-N-Prn), nasal angle (Cm-Sn/N-Prn) and vertical nasal angle (N-Prn/TV) which is against Mal- 
Ajami S et al.

koc et al. (18) in which no gender differences were reported for these three angles in young Turkish adults. However, our average values in the G-N-Prn, Li-Sm-Pg, N-Trg-Sn and G-Sn-Pg compared closely similar to Malkoc. Whereas, the average values for $\mathrm{Sn}$-Trg-Me were distinctly different (34-35 degrees in Malkoc vs. 39 - 40 degrees in this study). Despite the similarities in average values of certain angles, the Iranian population showed greater gender differences than the Turkish population. Given the close similarity in methods between the two studies, these data comparisons could suggest overall resemblances in certain facial patterns between Turks and Iranians, with greater gender differences in the Iranian population. One study by Fernandez et al. (1) on young Caucasians from Galicia found statistically significant sexual differences in the nasofrontal angle, nasal angle and vertical nasal angle. The presence of statistically significant sexual differences in these angles is consistent with our study of the Iranian population. However, there were no similarities in the average values for these angles, suggesting differences between these corresponding features in the Iranian and Galicia populations. In contrast, the nasal angle (Cm-Sn/N-Prn) showed sexual dimorphism in both studies and similar average values between the two studies (male subjects $=72.6 \pm 9$ degrees, female subjects $=76.2 \pm 6$ degrees). Thus, this suggests similarity in the nasal angle between the Galician and Iranian populations with corresponding gender dimorphisms. Where the nasal dorsum angle (N-Mn-Prn) also showed significantly $(\mathrm{P}<0.05)$ wider angles in males than in females, our study showed no statistically significant differences between genders. In another study by Anic-Milosevic et al. (25) on a young Croatian sub-population found distinct gender differences. It was found nasolabial (female subjects $=109.39$ degrees; male subjects $=$ 105.42 degrees; $\mathrm{P}=0.018$ ) and mentolabial angles (female subjects $=134.5$ degrees; male subjects $=129.26$ degrees; $\mathrm{P}$ $=0.019$ ) were larger in female subjects, which is different from our finding in the Iranian population where no statistically significant gender differences were found. In addition, when comparing these values with our study, the average values were similar, suggesting similarities in these corresponding features between the Croatian and Iranian populations. Wamalwa et al. (22) studied facial angular norms and sexual dimorphisms in a subpopulation of Kenyans and Chinese. Their finding was that the nasofrontal angle showed significant sex differences in both black Kenyans and Chinese, which is also consistent with our findings in the Iranian population. However, the average values for the nasofrontal angle between the two genders showed considerably large differences with our study (132 - 138 degrees versus 145 - 149 degrees in our study). In a sample of the Bangladeshi Galo population, Ferdousi et al. showed females had significantly higher values than the males in the nasofrontal angle, the nasomental angle and the angle of facial convexity, where we only found sexual dimorphisms in the nasofrontal angle of the Iranian population. Consistent with our study, Ferdousi et al. found no statistically significant gender differences in the nasolabial angle.Furthermore, we found that the average angle of facial convexity in this study (female subjects $=169.26 \pm 4.43$ degrees; male subjects $=158.65 \pm 12.17$ degrees) was similar to our study. Whereas, we found potentially substantial differences in the average values in the nasofrontal angles between our study (145 - 149 degrees) and Ferdousi et al. (130 - 138 degrees) (26). In a sub-population of young Igbo adults, Loveday et al. (7) showed significant gender differences in nasofrontal and cervicomental angles. However, we only found significant gender differences in the nasofrontal angle. In addition, the average cervicomental angle reported by Loveday et al. (91 degrees) was inconsistent and not considered similar in value with our findings (101 degrees). This was also the case with the nasofrontal angle where we found the Iranian population potentially larger than the Igbo population studied (averages of 145 - 149 degrees versus 130 - 134 degrees). Thus, this suggests potential differences in this angular measurement between the Igbo and Iranian sub-populations. Overall the above assessments show that the Iranian population we studied carries distinctive differences with sexual dimorphisms in comparison to other ethnic populations to which we compared our findings. In light of the objective of this study, we have characterized the angular facial norms in the young Iranian population with skeletal class I occlusion and found certain sexual dimorphisms in the angular measurements. Relative to surgical planning for cosmetic procedures and treatment of facial disorders, we believe our results can be used to re-assess the norms used by clinicians and improve the natural appearance for young Iranian subjects. These results confirm that a database for facial patterns used by clinicians in facial surgery for young Iranian subjects should be racially sensitive, if the goal is to attain a 'natural' facial appearance that is consistent with Iranian population norms. The differences in our results with benchmark studies of other ethnic groups further validate the need for racial-ethnically tailored cosmetic treatment plans. While this study achieves its objective by assessing preliminary data that shows trends and patterns in angular norms, we believe further work is needed to develop a data set that can be applied to clinical practice. This should entail assessment of a larger study population, in order to improve the confidence and resolution of facial norms in the young Iranian population. Such further study could be used to create a formal database and formulary for angular norms that surgeons can draw upon in clinical practice.

\subsection{Conclusion}

The results showed gender dimorphism in three of the measurements: the nasofrontal, the nasal and the vertical nasal angles. Another significant finding was the 
large variability for the mentolabial angle. The result of this measurement should be assessed with caution. Our results could be used as a reference guide for comparison with records of subjects that have the same soft tissue profile, ethnic characteristics and a dental class 1 occlusion and following the same photogrammetric technique. While our preliminary data set shows promise for future clinical application, a further developed database can allow orthodontics and surgeons to determine deviations from Iranian angular norms with angular photogrammetric profile analysis and improve treatment to establish a natural look.

\section{Footnote}

Funding/Support:This article was extracted from the thesis written by Sareh Mahdavi. and was financially supported by Shiraz university of medical sciences, international branch grant number: 2889 .

\section{References}

1. Fernandez RP, Smyth-C E, Suarez-Q. D., Suarez C. M. Angular photogrammetric analysis of the soft tissue facial profile. Eur J Orthod. 2003;25(4):393-9. [PubMed: 12938846]

2. Hershon LE, Giddon DB. Determinants of facial profile self-perception. Am J Orthod.1980;78(3):279-95. [PubMed: 6931492]

3. Varela M, Garcia-Camba JE. Impact of orthodontics on the psychologic profile of adult patients: A prospective study. Am J Orthod Dentofacial Orthop. 1995;108(2):142-8. [PubMed: 7625386]

4. dos Santos BM, Stuani AS, Stuani AS, Faria G, Quintao CC, Stuani MB. Soft tissue profile changes after rapid maxillary expansion with a bonded expander. Eur J Orthod. 2012;34(3):367-73. doi 10.1093/ejo/cjro21. [PubMed: 21441407]

5. Mandall NA, McCord JF, Blinkhorn AS, Worthington HV, O'Brien KD. Perceived aesthetic impact of malocclusion and oral selfperceptions in 14-15-year-old Asian and Caucasian children in greater Manchester. Eur J Orthod. 2000;22(2):175-83. [PubMed: 10822891]

6. Anic MS, Lapter VM, Dumancic J, Slaj M. Analysis of the soft tissue profile in Croatians with normal occlusions and well-balanced faces. Eur J Orthod. 2011;33(3):305-10. doi: 10.1093/ejo/cjq072. [PubMed: 20671069]

7. Loveday OE, Babatunde F, Isobo U, Sunday O, Ijeoma O. Photogrammetric analysis of soft tissue profile of the face of igbos in port harcourt. Asian J Med Sci.2011;3(6):228-33.

8. Sepehr A, Mathew PJ, Pepper JP, Karimi K, Devcic Z, Karam AM. The Persian woman's face: a photogrammetric analysis. Aesthetic Plast Surg. 2012;36(3):687-91. doi: 10.1007/s00266-012-9870-9. [PubMed: 22350308]

9. Kale VS. Angular photogrammetric analysis of the soft tissue facial profile of Anatolian Turkish adults. J Craniofac Surg.
2008;19(6):1481-6. doi: 10.1097/SCS.0b013e318188a34d. [PubMed: 19098536]

10. Uysal T, Baysal A, Yagci A, Sigler LM, McNamara JJ. Ethnic differences in the soft tissue profiles of Turkish and European-American young adults with normal occlusions and well-balanced faces. Eur J Orthod. 2012;34(3):296-301. doi: 10.1093/ejo/cjq165. [PubMed: 21273287]

11. Holdaway RA. A soft-tissue cephalometric analysis and its use in orthodontic treatment planning. Part I. Am J Orthod. 1983;84(1):128. [PubMed: 6575614]

12. Czarnecki ST, Nanda RS, Currier GF. Perceptions of a balanced facial profile. Am J Orthod Dentofacial Orthop. 1993;104(2):180-7. doi 10.1016/S0 889-5406(05)81008-X. [PubMed: 8338071]

13. Lines PA, Lines RR, Lines CA. Profilemetrics and facial esthetics. Am J Orthod.1978;73(6):648-57. [PubMed: 276268]

14. Arnett GW, Bergman RT. Facial keys to orthodontic diagnosis and treatment planning-Part II. Am J Orthod Dentofacial Orthop. 1993;103(5):395-411. [PubMed: 8480709]

15. Peck S, Peck L. Selected aspects of the art and science of facial esthetics. Semin Orthod.1995;1(2):105-26. [PubMed: 8935049]

16. Rhee SC, Kang SR, Park HS. Balanced angular profile analysis. Plast Reconstr Surg. 2004;114(2):535-44. [PubMed:15277828]

17. Anic-Milosevic S, Mestrovic S, Slaj M. Soft tissue profile typology: Results of the cluster analysis. J Craniofac Surg. 2009;20(4):12638. doi:10.1097/SCS.0b013e3181ace048. [PubMed:19625843]

18. Malkoc S, Demir A, Uysal T, Canbuldu N. Angular photogrammetric analysis of the soft tissue facial profile of Turkish adults Eur J Orthod. 2009;31(2):174-9. doi: 10.1093/ejo/cjn082. [PubMed: 19064675]

19. Farkas LG, Katic MJ, Forrest CR, Alt KW, Bagic I, Baltadjiev G, et al. International anthropometric study of facial morphology in various ethnic groups/races. J Craniofac Surg. 2005;16(4):615-46. [PubMed: 16077306]

20. Bergman RT. Cephalometric soft tissue facial analysis. Am J Orthod Dentofacial Orthop.1999;116(4):373-89. [PubMed: 10511665]

21. Peerlings RH, Kuijpers-Jagtman AM, Hoeksma JB. A photographic scale to measure facial aesthetics. Eur J Orthod. 1995;17(2):101-9. [PubMed: 7781718]

22. Wamalwa P, Amisi SK, Wang Y, Chen S. Angular photogrammetric comparison of the soft-tissue facial profile of Kenyan and Chinese. J Craniofac Surg. 2011;22(3):1064-72. doi: 10.1097| SCS.0b013e31821075d8. [PubMed: 21586946]

23. Park HS, Rhee SC, Kang SR, Lee JH. Harmonized profiloplasty using balanced angular profile analysis. Aesthetic Plast Surg 2004;28(2):89-97. doi: 10.1007/s00266-004-3125-3. [PubMed: 15156291]

24. Malkoc S, Sari Z, Usumez S, Koyuturk AE. The effect of head rotation on cephalometric radiographs. Eur J Orthod. 2005;27(3):31521. doi:10.1093/ejo/cjh098. [PubMed:15947234]

25. Anic-Milosevic S, Lapter-Varga M, Slaj M. Analysis of the soft tissue facial profile by means of angular measurements. Eur J Orthod. 2008;30(2):135-40. doi:10.1093/ejo/cjm116. [PubMed: 18263886]

26. Ferdousi MA, Mamun AA, Banu LA, Paul S. Angular Photogrammetric Analysis of the Facial Profile of the Adult Bangladeshi Garo. Advances in Anthropology. 2013;03(04):188-92. doi: 10.4236| aa.2013.34026 